\title{
Las bases éticas, políticas y jurídicas del orden mundial futuro
}

GREGORIO PECES-BARBA*

\section{NTRODUCCIÓN}

La obra de La Bruyère, Les Caracteres, que alcanzó en vida de su autor, en el siglo XVII, un tremendo éxito con gran número de ediciones, en su capítulo primero, «Des Ouvrages de l'Esprit», comienza con las siguientes palabras: «Tout est dit, et Ton vient trop tard, depuis plus de sept mille ans il y a des hommes et qui pensent» ${ }^{1}$. Whitehead decía, en ese mismo sentido, que «la historia de la cultura occidental son notas a pie de página al pensamiento de Platón». Frente a eso, las ideologías del fin de la historia quieren transformar todo el pasado en una tabla rasa y construir el futuro desde cero, como si la llamada «globalización» fuese un inmenso ataúd donde yacieran las aportaciones anteriores de la cultura y, en el ámbito que nos ocupa, de la cultura política y jurídica. Ninguno de esos enfoques es suficiente ni equilibrado para abordar el tema del nuevo orden mundial después del 11 de septiembre de 2001, con los terribles atentados a las Torres Gemelas. Después de superar los escrúpulos sobre la terminología «nuevo orden», que utilizaron los nazis y fascistas en los años veinte y treinta del pasado siglo, me parece que la reflexión no puede basarse solo en el pasado, y en que todo es imitación, ni tampoco prescindir de él y empezar desde cero. La Bruyere es demasiado conservador, y Whitehead demasiado provocador, como son simplistas los que olvidan la historia y los logros de la modernidad para el futuro. Creo que solo en la feliz integración de lo viejo que sirve y de lo nuevo integrador cabe avanzar, con racionalidad, en la construcción de un nuevo orden mundial. Por otra parte, señalar el horrible atentado de Nueva York como un momento eje del cambio histórico es discutible, porque ese horror especial y concentrado en un día es habitual y cotidiano en otras partes del mundo, donde niños mueren cada día masivamente y donde enfermos sin medicamentos ni cuidados son un fenómeno normal desde hace muchos años. Es verdad que el 11 de septiembre golpeó en el corazón del imperio y que fue un acto de una crueldad inusitada que se vivió, en tiempo real, en todo el mundo; un aldabonazo de atención para la necesidad del cambio de los comportamientos y de muchas reglas del juego económico, político y jurídico.

Es verdad que la revolución de las comunicaciones, la globalización económica y la mundialización de los mercados marcan, con nuevos caminos, la evolución de la humanidad, pero esta sigue estando 
conformada por hombres situados en la historia que siguen siendo, desde mi punto de vista, el referente central para interpretar el cambio que nos viene, y para ello hay que contar con todas las luchas anteriores que han avanzado en los procesos de humanización y de racionalización. Probablemente, el déficit de humanización que identifica a la globalización y a la revolución tecnológica debe ser compensado con este repaso a las conquistas liberadoras del pasado, lo que supone, en resumen, una vuelta a la Ilustración y a todos sus desarrollos en los siglos XIX y XX.

Es verdad, como dice Popper, que «el significado de la historia es algo que escogemos [...] Naturalmente, ninguna Diosa de la historia nos salvará de las consecuencias de nuestras propias acciones»². Por otra parte, hay que desconfiar de los que trabajan al servicio de intereses, aunque sean respetables, pero parciales, y que no tienen como objetivo central el progreso del conocimiento desde la probidad intelectual. Y es especialmente negativo cuando los intereses se hacen pasar o se enmascaran como principios. Es verdad que estamos ante un momento clave en la evolución de las sociedades y que vivimos en el corazón de la historia, pero esa no es una circunstancia nueva; en otros muchos momentos se han sentido situaciones semejantes. Incluso los asaltantes de la Bastilla lo decían jubilosos: «Estamos en el corazón de la historia». Seguramente, los hombres del Renacimiento, o los del Descubrimiento de América, o de la Revolución Francesa, o de la Revolución Rusa se pensaban igualmente especiales. Por eso, y como ocurrió siempre antes, desmitifiquemos la especialidad de este momento y devolvámosle la normalidad de la construcción histórica de la humanidad. La polémica de los historiadores en el tránsito hacia la modernidad, con las dos teorías extremas - la que defendía la ruptura y la que defendía la continuidad-, puede servirnos de modelo. Por eso me inclino, como nos enseña la evolución del mundo moderno a partir del Renacimiento, a tomar en consideración, para analizar el nuevo orden mundial en el siglo XXI, las bases que la historia nos ofrece para fundamentar el futuro, desde la perspectiva de la continuidad de las culturas y de su ruptura, en una dialéctica integradora donde cada vez los nuevos tejidos se elaboran con hilos viejos y con hilos nuevos. José Antonio Maravall, en Antiguos y modernos, lo dirá con palabras precisas: «Sólo una cultura que [...] se reconoce a sí misma como heredera, puede organizar intelectualmente una concepción del progreso. Sólo cuando se tiene un punto de referencia, constituido en este caso por el nivel heredado, se puede observar el movimiento de la historia y puede apreciarse éste como una marcha hacia delante» ${ }^{3}$.

Desde mi punto de vista, una construcción racional y humana del nuevo orden mundial debe partir de las conquistas de la modernidad, de las

2 Popper, Karl R. «Un enfoque pluralista de la filosofía de la historia». En El mito del marco común. En defensa de la ciencia y de la racionalidad. Marco Aurelio Galmanini (traductor). Barcelona: Paidós, 1997, p. 137.

3 Consúltese Maravall, José Antonio. Antiguos y modernos. Madrid: Sociedad de Estudios y Publicaciones, 1966, p. 363. 
luces y de la razón irrenunciables, si ese nuevo orden pretende proseguir el proceso de humanización y de racionalización. Esas conquistas forman parte de un movimiento de emancipación de la humanidad para permitir al hombre andar sin apoyo externo, sin muletas ni andaderas. «Sapere ande», como decía Kant al responder a la pregunta: «iqué es la Ilustración?». Son irreversibles, y en cuanto se deterioren o se desconozcan estaremos retrocediendo en el camino de la liberación intelectual y de la liberación política. De todas esas conquistas que ponen de relieve la dignidad humana y los elementos sociales políticos y jurídicos que la hacen posible, podemos decir, salvadas las distancias, lo que decía Paul Eluard de las víctimas del holocausto: «Si el eco de su voz se debilita, pereceremos».

I.

Los elementos decisivos, perdurables e imprescindibles para el futuro son la dignidad de la persona humana, la laicidad, la distinción entre ética pública y ética privada, y el equilibrio entre los valores de la libertad, la seguridad, la igualdad y la solidaridad, que son el desarrollo de las exigencias de la dignidad humana. Estas son la esencia del pasado que todos debemos promover para garantizar un orden mundial futuro humano y habitable, al servicio de la dignidad, lo que supone integrarlas con la globalización, con las nuevas tecnologías, con la represión del fenómeno terrorista, con los movimientos migratorios, con las diferencias entre países e individuos ricos o pobres; en definitiva, con el destino de la humanidad.

Aunque estamos ante un concepto que surge en la Grecia clásica y que bautizará el cristianismo, con la atribución al hombre de la filiación divina, como hijo de Dios, la plenitud y sentido actual de la dignidad empezará a asentarse a partir del tránsito hacia la modernidad. Aquellos viejos hilos, con los nuevos que se añadirán con el humanismo y la Reforma, serán el material del nuevo tejido de la dignidad humana. Es la idea del hombre centro del mundo, raíz de su dignidad que lo diferencia de los restantes animales, y que será inseparable, a partir de la consolidación de la tolerancia religiosa en los siglos XVI y XVII, de la noción de hombre centrado en el mundo, es decir, del hombre secularizado, que abre la puerta a la noción de laicidad, que es una de las razones de distinción entre ética pública y ética privada. Kant vinculará al hombre ilustrado con el que no necesita guía, y por consiguiente vincula su dignidad con su autonomía, es decir, con su elección libre de su idea de salvación, de bien o de virtud.

Dignidad humana y laicidad serán desde entonces inseparables, y la idea de que somos seres de fines y no podemos ser utilizados como medios, y que no tenemos precio, se debe insertar en ese contexto. 
El tema es especialmente sensible, porque el atentado del 11 de septiembre, uno de los puntos de partida de este foro, tiene dimensiones, fundamentos o excusas religiosas, de sectores del islam, contra el cristianismo, lo que apunta a nuevas violencias de origen religioso organizado. Esta situación marca claramente la importancia de ese proceso de secularización de la vida europea y atlántica para el futuro, y obliga a llamar la atención de nuevo sobre conceptos como el de tolerancia y libertad religiosa e ideológica. Entonces fue la intransigencia de las iglesias y confesiones cristianas, y también la cruzada igualmente religiosa contra el turco, entre otros escenarios, y hoy es la existencia de fundamentalismos religiosos que quieren acabar con sus enemigos o que mantienen formas de extrema brutalidad en la represión de delitos - como la lapidación por adulterio-, a causa de la identificación entre pecado y delito. También en España el modelo del Estado-Iglesia, que vinculaba la unidad política con la unidad religiosa, trajo a nuestro país persecuciones y atentados sin cuento durante siglos contra la dignidad humana de los heterodoxos. Además, esa dificultad de hacer compatible la dignidad humana con las estructuras eclesiásticas no es exclusiva del islam, sino que se mantiene en ámbitos de confesiones cristianas y especialmente en la Iglesia católica, donde la diferencia entre jerarquía y fieles, o la de una concepción del bien que desconoce la distinción entre ética pública y ética privada, y que pretende convertir a todos los ciudadanos en creyentes, es difícilmente compatible con la igual dignidad de todos los seres humanos. La encíclica «Vehementer Nos», de Pío X, año 1906, en la que se distingue entre los pastores y el rebaño en el interior de la Iglesia, y se señala que estos últimos solo tienen como misión obedecer a los pastores, es difícilmente compatible con la dignidad, como lo es la inferioridad de la mujer respecto del hombre, al impedirle el acceso al sacerdocio y a la jerarquía episcopal ${ }^{4}$.

Dignidad humana y laicidad son compatibles con la religiosidad individual, con el fenómeno religioso como vinculación de fe entre cada persona y Dios. Es más, el último de los rasgos que nos convierten en más dignos consiste precisamente en nuestra vocación de ética privada, de buscar un camino de salvación, de virtud, de bien o de felicidad, que puede ser religioso o laico. Cuando esa religiosidad es administrada por una estructura jerárquica, jurídicamente organizada con cánones y reglas, y que sostiene una verdad como indiscutible y procedente de Dios, que ella interpreta, existe un claro y evidente peligro de que se considere por encima de las reglas del juego de las constituciones, como

4 El párrafo de la «Vehementer Nos» que interesa dice lo siguiente: «La escritura nos enseña y la tradición de los padres confirma que la Iglesia es el Cuerpo Histórico de Cristo [...] en el seno del cual hay jefes que tienen plenos y perfectos poderes para gobernar, para enseñar y para juzgar. De lo cual resulta que esta sociedad es desigual por esencia, es decir, es una sociedad que comprende dos categorías de personas, los pastores y el rebaño; los que ocupan un rango en los distintos grados de jerarquía y la multitud de los fieles. Y de tal modo son distintos entre sí, que sólo en el cuerpo de los pastores reside la autoridad y el Derecho necesarios para promover y dirigir a todos los miembros hacia el fin de la sociedad; en cuanto a la multitud, ella no tiene otro deber que el de dejarse conducir, y, rebaño dócil, seguir a sus pastores». Consúltese también la reciente Constitución de la Ciudad del Vaticano de 2001, artículo primero. 
señala un documento de la Conferencia Episcopal Española de 1996. Esos documentos no se suelen leer, pero cuando dicen que esas verdades están por encima de las coyunturales mayorías parece que deben ser tomados en serio por el peligro que suponen para esa idea del hombre centro del mundo y centrado en el mundo, que es el modelo respetuoso con la dignidad humana.

Herbert George Wells (1866-1946), el gran novelista inglés y socialista humanista, dice unas palabras muy duras sobre la estructura eclesiástica como impedimento para la religiosidad individual de personas a las que se respeta la dignidad: «Hay cuatro estadios entre la fe y la incredulidad: el de los que creen en Dios; el de aquellos que dudan de él, como los agnósticos; el de los que lo niegan, que es el caso de los ateos, quienes al menos dejan vacante su lugar; y por último, el de aquellos que han instaurado una Iglesia en el puesto de Dios; éste es el último ultraje de la infidelidad $»^{5}$. Es verdad que puede haber iglesias u otras comunidades religiosas que no sustituyen a Dios, ni pretenden obligar a todos a ser creyentes. El budismo o algunas confesiones protestantes, y también los heterodoxos de la Iglesia católica, como los erasmistas, representan ese tipo de comportamientos, compatibles con la defensa de la dignidad humana y de la laicidad. La barrera pública frente a esa vocación expansiva de algunas iglesias tiene carácter jurídico constitucional y está formado por la separación entre poder religioso y poder político, que es una asignatura pendiente en el islam.

Parece que el nuevo orden político y jurídico debe garantizar la idea de dignidad humana y de laicidad, para evitar violencias y posiciones que dañen o destruyan a personas, para evitar que iglesias, confesiones religiosas y concepciones del bien pretendan incorporar sus verdades a la organización de los criterios sobre poderes, principios o derechos, que corresponde en exclusiva a la ética pública a través de las reglas de juego y de las instituciones democráticas. En concreto, para hacer posible que seamos seres de fines y que no tengamos precio, se deben garantizar los contenidos de la dignidad que nos distinguen de los restantes animales: nuestra capacidad de elegir, de construir conceptos generales y de razonar, de crear belleza por el arte, o la literatura, de comunicarnos y de dialogar, y de buscar el camino de nuestra ética privada.

Solo podemos ser dignos, personas de fines que no tienen precio y que no pueden ser utilizadas como medios, si la ética pública orienta al poder y al Derecho para facilitar nuestra capacidad de elección, y eso supone desarrollar derechos fundamentales como el derecho a la educación, el de la libertad de pensamiento y el de opinión, el de la libertad ideológica o religiosa, y el de la libertad de movimientos o de circulación. Ese orden mundial futuro no puede mantener la incomprensible y arbitraria situación de que puedan circular los capitales y establecerse

5 Es de su trabajo Guerre et avenir, que cita Fernando de los Ríos en un artículo que publica en la Revista España, $\mathrm{N}^{\circ} 312,1922$, pp. 7 y 8. 
en cualquier país y que no puedan hacerlo las personas. Aquí apuntamos algo que, vinculado con la igual dignidad de todos, exige que la moralidad que informe las relaciones sociales sea la ética pública y no la economía como ética. Cuando se trata de la vida y del desarrollo de las personas, no pueden criterios económicos — como la inflación, la deuda pública o el déficit cero- decidir por encima de criterios de la ética pública - como el igual trato y la igual consideración o la satisfacción de las necesidades básicas - sin que se ataque en sus raíces a la dignidad humana.

Lo mismo podemos decir de nuestra capacidad de construir conceptos generales y de razonar temas que nos distinguen de los demás animales, y así cualquier sistema político y jurídico en el nuevo orden internacional deberá facilitar el derecho a la educación, la libertad de cátedra, la ciencia y la investigación.

También para garantizar la creación de belleza o para comunicarnos y para dialogar, será necesario mantener y potenciar principios y derechos como la libertad de creación artística, el sistema parlamentario, la libertad de expresión, de opinión, de información o de reunión.

Finalmente, para garantizar a cada uno la búsqueda de su ética privada, de su idea del bien, de la virtud o de la salvación, es necesario arraigar la tolerancia, el respeto mutuo y la libertad ideológica o de cultos, además de tomar todas las medidas jurídicas — separación Iglesia-Estado, pluralismo político, etcétera- que impidan el arraigo del fundamentalismo religioso contrario a la sociedad abierta, sede de la dignidad humana.

II.

El reconocimiento de la distinción entre ética pública y ética privada es una condición para la existencia de sociedades democráticas libres, es decir, que se organicen con respeto a los cuatro grandes valores que, a partir de la Ilustración, afloraron como núcleo de la ética pública, que se realiza y se convierte en eficaz a partir de la acción política y del Derecho. Esta distinción es consecuencia del proceso de secularización que arranca del tránsito a la modernidad, de la separación entre Derecho y moral que formuló Tomasio, y que es el signo de que el Estado no puede ser un medio, a través de la coacción institucionalizada, para establecer obligaciones religiosas para los ciudadanos en favor de una iglesia. Es una de las grandes conquistas de la modernidad que aparece ya en la Carta sobre la tolerancia de John Locke, de 1689, y que se consolidará desde la laicidad en la Revolución Francesa y desde la separación Iglesia-Estado en la Revolución Americana. La ética pública marca los objetivos del poder y de su Derecho, y tiene solo fines para favorecer el desarrollo de la dignidad humana. La ética privada es la ética individual, el camino que recorre cada persona para alcanzar su plenitud moral, que 
es el último ámbito de su dignidad. El orden mundial del futuro -en el ámbito de los Estados, en su superación en sociedades más amplias, como la Unión Europea, e incluso en la utopía kantiana del Estado cosmopolita - solo será democrático, propio de la sociedad libre y abierta, si respeta la distinción.

Cuando la ética pública desborda sus límites y pretende convertirse también en la ética privada de sus ciudadanos, estamos ante el reduccionismo totalitario, en el cual se priva a sus ciudadanos de sus creencias personales y se los obliga a compartir las creencias del Estado o del partido único. En el caso de los fascismos, será el Estado el que invada las conciencias individuales. «No hay salvación fuera del Estado», dirá Mussolini siguiendo a Gentile. En el caso del leninismo, será el partido, vanguardia del proletariado, aquel que marcará la moralidad privada. En el discurso de Lenin a las juventudes comunistas rusas de 1920, o en otros de Mao Tse Tung, se encuentran los rasgos de este totalitarismo partidario frente al totalitarismo estatalista de los fascismos.

Cuando, al contrario, la ética privada de una iglesia, de una concepción del bien, de una filosofía comprehensiva, pretende que todos los ciudadanos sean creyentes, estamos ante el fundamentalismo eclesiástico y religioso. En los sucesos del 11 de septiembre subyacía esta patología, desde una visión belicosa del islam, desde la dialéctica del odio, y de la contraposición amigo-enemigo. La irreversible verdad que defienden, apoyada en la autoridad de Dios, otorga a sus pretensiones una firmeza y una seguridad que son difíciles de encontrar en el ámbito político. Al tiempo, esa convicción relativiza el valor de la constitución y del resto de las normas del juego político y jurídico. iCómo se puede entender, si no, la seguridad con la que el señor Cardenal de Madrid afirmó hace pocas semanas ante el Rey, al recordarle sus obligaciones, que es «Su Majestad Católica», heredero de la tradición confesional de la monarquía española? Una tan flagrante violación de la separación de poderes y de la esencia de la constitución solo se puede sostener desde unas creencias muy firmes, arraigadas en verdades que no se consideran discutibles ni sometidas a críticas. ¿Cómo se puede explicar, si no, la facilidad y la tranquilidad de espíritu de los señores obispos, cuando despiden, y en consecuencia violan derechos fundamentales, a profesores y profesoras de religión al alegar falta de espíritu religioso o vinculación con partidos políticos laicos? Tampoco se puede entender esa flagrante violación de derechos fundamentales como la intimidad, el derecho al trabajo o la seguridad jurídica.

En el ámbito católico, además, el agustinismo político niega la posibilidad de un conocimiento humano autónomo para conocer la verdad, que solo puede aparecer con la verdadera ley, que es la luz de la fe que administra la Iglesia. Por eso, el principio de ética privada de «la verdad nos hará libres» se traslada al ámbito público y se presenta como verdad para la convivencia social y política lo que es verdad religiosa para el

LAS BASES

ÉTICAS,

POLITICAS Y JURÍDICAS DEL ORDEN MUNDIAL FUTURO 
ámbito de la ética privada. Cuando se dice, como hemos visto, que la Iglesia es depositaría de verdades incontrovertibles, por encima de las coyunturales mayorías, se está participando de estas ideas.

El mantenimiento de ese modelo — sea en su versión light, que es la católica, o en su versión más dura, que es la islámica - impedirá claramente una organización democrática en el orden mundial del futuro. Mucho más dura será la situación cuando las dos patologías coincidan en un mismo ámbito, y el poder político totalitario y el fundamentalismo se unan en un tipo de Estado-Iglesia. En ese caso, la militancia política y la creencia religiosa serán una misma cosa.

El depósito de sabiduría política y jurídica que recibimos de la modernidad orienta las bases del orden mundial futuro al sostenerlo sobre la idea de dignidad humana, tal como la hemos caracterizado aquí, desde la laicidad y la distinción entre ética pública y ética privada, con un espacio amplio para la religiosidad individual de los creyentes, compatible con ese marco ideológico pero con restricciones y límites para la acción organizada de las iglesias cuando excedan de su ámbito propio e interfieran en el ámbito público. Así, la separación entre Iglesia y Estado llevada a sus últimas consecuencias, el pluralismo ideológico y de religiones compatibles, el respeto y la tolerancia, son dimensiones inseparables del orden del futuro.

III.

Hemos visto que el principio para la acción en la ética pública que orienta los fines de la acción política y del Derecho no puede ser «la verdad nos hará libres», ni podrá ser tampoco la base del orden mundial futuro, si no queremos que el fundamentalismo religioso se potencie y se creen los gérmenes para un nuevo período de guerras de religión. Más bien, ese principio será el contrario: «la libertad nos hace más verdaderos», porque efectivamente el valor libertad será el núcleo central — tal como se ha ido construyendo a lo largo de la modernidad— que se proyectará para identificar, en las condiciones ambientales de nuestro tiempo, a las estructuras políticas y jurídicas y a las relaciones sociales en el futuro. Los restantes grandes valores que seguirán siendo el contenido básico de la ética pública — la igualdad, la solidaridad y la seguridad — solo se entienden, y creo que se entenderán, en referencia a la libertad, que es el valor que se identifica con el desarrollo de la dignidad humana. Así que seguiremos hablando de libertad igual, de libertad solidaria y de libertad segura.

Como decimos, el valor libertad se ajusta y expresa el desarrollo del itinerario de la condición humana, que consolida su dignidad a partir de la libertad de elección, la capacidad de elegir de la que hablábamos como primer contenido de la idea de dignidad, para llegar a la libertad moral, que llamábamos capacidad para elegir una ética privada. Este itinerario 
de la libertad desde la libertad inicial, psicológica o de elección —lo que San Agustín llamaba la «libertas minor»-, hasta la libertad final, la «libertas maior», la libertad moral, esa autonomía o independencia moral que se adquiere o que se intenta al menos con una buena elección, necesita de una libertad medial, instrumental, que facilite la organización social, política y jurídica que haga posible ese recorrido, que es lo esencial del desarrollo humano digno. En ese itinerario, la persona experimenta también los otros tres rasgos de su dignidad: su capacidad racional, su creatividad, y su diálogo y su comunicación con los demás, que son aspectos indispensables para el buen desarrollo del recorrido de la libertad, que es el de la maduración personal como seres dignos. Dignidad y libertad son inseparables y son dos términos equivalentes que necesitan de la libertad instrumental, que es la libertad social, política y jurídica, porque la persona no se hace aislada sino en el marco de la vida social. Por eso, el valor libertad como núcleo de la ética pública será también la base del futuro de las sociedades políticas y, en su caso, del orden mundial. Desde él se tendrán que analizar conceptos jurídicos y políticos como el de soberanía, que ha marcado hasta ahora a los Estados para identificar que no reconocen superiores y que tienen en su ámbito territorial el monopolio del uso de la fuerza legítima, como dice Weber. Otros conceptos, como Estado, nación o como la actual situación de las organizaciones internacionales, tendrán que valorarse en el futuro en dependencia del concepto libertad.

Si esos conceptos, en alguna de sus dimensiones reales, son un obstáculo para el desarrollo de la libertad, de la elección moral o social, política y jurídica, deberán adaptarse e incluso desaparecer, porque esa libertad integralmente entendida e identificada con la dignidad humana es el imperativo ético radical al que deben ceder todos los demás para la construcción de las bases de la sociedad futura. Y lo mismo debemos decir de otros aspectos de la realidad social y económica, como el mercado, la libertad de empresa o de industria, la organización de las finanzas, las relaciones de trabajo o la globalización. El referente ético de la libertad debe marcar su supremacía respecto de cualquier regla técnica, económica o de otro tipo, derivada de la propia condición de esos conceptos.

Naturalmente, esa supremacía del valor libertad, que como recordamos se adjetiva como libertad igual, solidaria y segura, no puede pretender la tarea imposible de escalar al cielo, y debe contar con los conceptos de escasez y abundancia, igualmente presentes en todo el debate moderno sobre la organización social y la acción del Derecho. Recuérdese entre los clásicos modernos a Hume y a su sección tercera «Sobre la justicia» de su Encuesta sobre la moral. Entre los modernos, recuérdese El concepto de Derecho de H. L. A. Hart. Por eso, la eficacia de la libertad igual se debe medir por los medios económicos para llevarla a la práctica. 
La libertad social, política y jurídica tiene tres principales dimensiones:

- es libertad protectora, que crea un ambiente de autonomía, un coto cerrado ante la acción y a la intervención de terceros, y es una libertad que necesita pocos medios para realizarse;

- es libertad de participación, que establece los cauces para la acción de los titulares en la formación de la voluntad de los órganos públicos, y tampoco necesita medios económicos cuantiosos; y

- es libertad de prestación, que establece los medios y formula los cauces, por medio de derechos de crédito, para ayudar a la satisfacción de las necesidades básicas radicales, de mantenimiento y de mejora de aquellos que no pueden satisfacerlas por sí mismos. Esta es la dimensión más cara de la libertad y la más objetada y discutida por los liberales partidarios del estado mínimo.

Este va a ser uno de los aspectos más polémicos de la construcción de la sociedad futura. Aquí entra en juego el valor igualdad, porque si se prescinde de la libertad prestación ya no cabrá la libertad igual, y estaríamos renunciando a que una parte de la humanidad, probablemente la mayoría, fuese excluida de alcanzar las dimensiones de la dignidad. Estaríamos dando la razón a Malthus y quitándosela a Rousseau, por lo que este conflicto también se resolvería, como tantos otros, desde los clásicos. Habríamos aceptado la horrible filosofía del banquete, con la parábola que Malthus incorporó en la segunda edición del Ensayo sobre la población, que excluía de los beneficios del banquete a todos los pedigüeños que se agolpaban a las puertas de la sala y que dificultaban el disfrute pacífico de los invitados. Habríamos excluido el esfuerzo constante de Rousseau por evitar una sociedad en la que hubiera hombres tan ricos que pudieran comprar a los demás y otros tan pobres que necesitasen venderse. Probablemente este va ser uno de los grandes debates del futuro y ya lo es del presente, en el ámbito de la globalización: si es parcial y no supone al mismo tiempo una paralela universalización de la libertad igual tal como la hemos entendido aquí, configurará un orden social con libertad solo para un sector por su carácter desigualitario. En este contexto, además, estará la fuente de los futuros conflictos y de la violencia. Un terrorismo que esgrimiese estos argumentos podría tener acogida en las masas hambrientas del tercer y del cuarto mundo, y en los sectores marginales de los países desarrollados, y podría acabar en la tercera gran revolución después de la francesa y de la rusa. Cuando Malthus habla de los invitados al banquete, no explica por qué esos y no otros son los invitados.

Este es el punto más caliente de la configuración del orden futuro, y quizás la brutal acción del 11 de septiembre puede ser una llamada de atención para que la ceguera de los más egoístas, o de los más doctrinarios del neoliberalismo económico, se disipe o al menos se atenúe y se libren, 
por la comunidad internacional, por los Estados y por los poderosos de la Tierra, medios para avanzar en la universalización de una libertad igual que alcance a la mayor cantidad posible de personas.

IV.

En relación con el valor igualdad, hay que partir de la afirmación de que toda vida humana vale igual y que no existe una más importante que otra. Este principio moral contrasta con una realidad de muchas personas que sufren sin necesidades básicas satisfechas, que viven en la miseria, en la ignorancia, impotentes para acceder a un nivel de vida mínimo, con lo que parece que la libertad igual exige un gran esfuerzo de cohesión y de elevación de su condición al nivel de la dignidad, lo que exigirá una gran aportación de medios y de acción igualadora y solidaria. Existe un precedente en los países desarrollados, donde por influencia del socialismo o simplemente para prevenirse frente a él se produjeron esfuerzos de igualación y de integración, que han logrado cohesionar a esas sociedades y han elevado y dignificado al antiguo proletariado. Existe un nuevo proletariado en la dimensión global de todo el universo, y por eso el problema que se resolvió en el ámbito de los Estados, con poca presencia internacional, en los siglos XIX y XX, tiene otro escenario y otros actores: es el mundo entero y los pobres del mundo. Un planteamiento imparcial, desde la razón, será fundamentalmente igualitario y tenderá a favorecer a los más desprotegidos, con las prioridades que he señalado para alcanzar un nivel mínimo de libertad igual para todos, que no exija sacrificios desproporcionados a quienes tienen que aportar los medios necesarios y que no favorezca el exceso en las peticiones. Un esfuerzo conjunto de la comunidad internacional, de los Estados y de los intereses privados, debe planificarse para alcanzar esos objetivos que aproximarán a toda la humanidad a los parámetros de las relaciones entre ricos y pobres en los países desarrollados. Esta acción del valor de igualdad se puede ver favorecido si la comunidad internacional adquiere más poderes y se avanza hacia poderes regionales o universales que potencien la obligatoriedad del Derecho internacional, o que lo transformen en Derecho interno de comunidades regionales que reciben transvases de soberanía y que aspiran, en el futuro, al monopolio del uso de la fuerza legítima en el ámbito de su competencia. Ese esfuerzo de unificación política y jurídica progresiva tiene que ser también uno de los objetivos centrales del orden político y jurídico futuro, porque, como se ve, es un elemento indispensable para avanzar en la implantación del valor libertad igual.

Pero nada será posible si no se logra cambiar la mentalidad de los más poderosos, en el sentido que indica un punto de vista imparcial para alcanzar un compromiso justo de convivencia. Si estos se atrincheran tras sus intereses y logran encontrar teóricos dispuestos a justificar esos intereses como principios, el avance será muy complejo. Esto se evitará

LAS BASES

ÉTICAS,

POLITICASY

JURÍDICAS DEL

ORDEN MUNDIAL

FUTURO 
solo si las personas acomodadas, desde los más ricos hasta los miembros de profesiones liberales, logran comprender que las desigualdades, de las que los que sufren no son responsables, deben ser corregidas. Solamente entonces se entenderá que las ventajas o desventajas con las que se nace, como dice Thomas Nagel, y que forman la estructura básica en la que se debe vivir, no pueden ser consideradas como bienes o males que derivan de nuestra responsabilidad, y por lo tanto deben ser tratados desde la igualdad para hacer posible la libertad igual. Hay que acabar con las actitudes que impiden avanzar hacia esa libertad igual. Son los beneficiarios en la actividad económica o sus herederos que piensan que su situación se debe a su mérito o a su suerte, y que nunca piensan que pueden ser titulares de bienes mal adquiridos. Nagel, en Equality and Partiality, lo dirá de forma magistral:

Los beneficiarios estiman que pueden legítimamente contarse entre los que tienen la suerte de poseer capacidades naturales y triunfos que proceden tanto de su educación, como de su situación social, y que, bien explotados, les han dado ventaja sobre sus competidores, que les han valido en consecuencia una retribución. Los otros han tenido menos suerte. Es la vida $[\ldots]^{6}$.

Otros ni siquiera se plantean esa reflexión. En todo caso, estas mentalidades son un obstáculo serio para ese objetivo de alcanzar la libertad igual. Harold Laski, el fabiano, profesor de Derecho y Ciencia Política, amigo de Heller y de Fernando de los Ríos, decía en los años treinta, cuando dirigía la London School of Economics, que los conservadores ingleses eran personas cuya mentalidad nunca había sido manchada por el pensamiento. Si los obstáculos para la comprensión de la necesidad de la libertad igual, incluso para la supervivencia del propio sistema, tienen esos componentes, estamos ante un gran peso que, como decía Baudelaire, necesitaría el coraje de Sísifo.

Por ello el componente de la educación tiene que ser decisivo para evaluar esas situaciones y erradicar esas mentalidades de sociedad privada, de aquellos que se consideran dueños de sus riquezas, cuando solo son, como decía Luis Vives, despenseros que deben reconocer al otro como tal y con el derecho a una igual dignidad. Y allí donde no llegue la educación deberá llegar el Derecho, para impulsar estructuras que canalicen la libertad de prestación.

V.

Para esa tarea de generalizar la libertad, los instrumentos de los poderes públicos son insuficientes, y debe propiciarse, con la educación y con el Derecho, una acción social solidaria en la que los grupos sociales, las asociaciones y las organizaciones no gubernamentales contribuyan, con 
el Estado y con su Derecho, a facilitar la satisfacción de las necesidades básicas. Esta participación y esta cooperación social son las que se añaden con el valor solidaridad, que debe extenderse a las relaciones entre Estados, y atenuar las estrictas reglas económicas de los préstamos y de las ayudas internacionales con esta contribución de la justicia.

La solidaridad es un idea antigua que encontramos en Aristóteles, en estoicos como Cicerón o Séneca, y que se apoya en el amor, en la unidad, en la comunicación o en la hermandad, y se extiende a la modernidad desde el humanismo jurídico, los utopistas del Renacimiento o el iusnaturalismo racionalista, que la prolongó hasta la Ilustración. El reconocimiento del otro como tal otro - frente a la idea egoísta de la utilidad exclusiva y excluyente- está en su raíz, que se potencia en contraposición con la defensa que desde Adam Smith se hace, con la economía política, del interés propio, del ánimo de lucro, del egoísmo y del contrato como única forma de comunicación entre los individuos. Cuando se piensa que las dimensiones morales no afectan a la economía, o que las relaciones entre los hombres tienen que sustituirse por el intercambio entre las cosas y por, únicamente, el libre juego de la autonomía de la voluntad, no queda sitio para la solidaridad. Como antítesis, se potencia en ese escenario la nueva solidaridad, que ya no será una virtud privada, sino que se convertirá en un valor de la ética pública.

La mentalidad de sociedad privada forma parte de las dimensiones del capitalismo que permanecen hoy, y que sin duda pretenden perpetuarse en el futuro. La caída de los regímenes comunistas, por su carácter totalitario, ha contribuido decisivamente a la idea del éxito de ese capitalismo egoísta frente a un capitalismo más solidario, que podría ser compatible en su globalización con una generalización solidaria de los beneficios que abriría el paso a una libertad igual y solidaria para todos. Como ya hemos visto, aquí está una de las claves del futuro, que será moral o que, en caso contrario, podría llevarnos a una catástrofe. El 11 de septiembre no puede ser solo el momento horrible de un holocausto de vidas inocentes, sino el principio de la toma de conciencia de una situación insostenible de pobreza, de analfabetismo y de desesperación que puede aliar a esas masas, que no tienen nada que perder, con esos profetas de la muerte, de la guerra santa y del exterminio de los enemigos, que para ellos son los ricos y los explotadores.

Por eso, la solidaridad es un componente necesario del orden político y jurídico futuro, es compatible con las posiciones individualistas y corrige el contractualismo clásico —entendido como un individualismo egoísta y aislacionista—. Potencia sociedades donde el otro es un prójimo que forma parte de nuestra misma comunidad, es incompatible con sistemas cerrados y con concepciones totalizadoras y excluyentes, y fortalece la tolerancia y el pluralismo. La solidaridad contribuye a crear en la sociedad cauces de comunicación que permiten un diálogo ilustrado entre personas que se respetan y se reconocen, y que contribu-

LAS BASES

ÉTICAS,

POLITICAS Y

JURÍDICAS DEL

ORDEN MUNDIAL

FUTURO 
yen, en ese esquema compartido, a poner en común, a discutir y a formar criterios morales que superan la pura individualidad y que fomentan la cultura. Más que derechos, fundamenta deberes y solo indirectamente derechos, aunque está en la raíz de dimensiones decisivas para el futuro, como el respeto al medio ambiente y al patrimonio genético.

Asimismo, favorece la extensión de los derechos a todo el universo y a todas las personas, para salir del eurocentrismo desde la idea de humanidad. Esa mentalidad egoísta se rompe con la educación en la solidaridad, porque, como dice John Rawls, «hay una moralidad de la asociación en la que los miembros de la sociedad se consideran entre sí como iguales, como amigos y asociados reunidos en un sistema de cooperación, del que se sabe que es beneficioso para todos y que está regido por una común concepción de la justicia» 7 . Con esta cooperación que potencia la libertad igual, la sociedad del futuro podrá hacer frente a los peligros de una marginación de la mayoría en los beneficios del desarrollo que permita a todos la oportunidad de ser libres.

VI.

Pero la libertad en el orden político y jurídico futuro tiene que ser segura. El Estado moderno surge cabalmente a través del monopolio del uso de la fuerza legítima para garantizar la seguridad. La seguridad medieval se aseguraba por la Iglesia, que garantizaba la salvación y administraba cómo debíamos pasar por este «valle de lágrimas». También la garantizaban los gremios y las corporaciones donde los hombres nacían, aprendían y trabajaban, hasta su muerte, protegidos por sus estrictas reglas. Finalmente, una de las obligaciones del señor en el régimen feudal era dar seguridad a sus vasallos. El Derecho, que era la búsqueda de lo justo en el caso concreto, lo aseguraba con la pluralidad de poderes y de jurisdicciones. Pero en el tránsito a la modernidad, cuando las guerras de religión rompieron la unidad y la seguridad de la Iglesia, y el individualismo fue quebrando los vínculos gremiales y feudales, la seguridad jurídica - como búsqueda de la paz y del orden — sustituyó a la vieja seguridad medieval, con el Estado como poder único, supremo y fuerte. En el primer modelo del Estado moderno como Estado absoluto, la seguridad estaba separada de la libertad. Solo se garantizaba la tranquilidad, el orden y la paz, pero no la libertad. Incluso ese aseguramiento de la paz se producía en detrimento de la libertad, porque el monarca suprimió las libertades estamentales y los privilegios medievales.

Pero libertad y seguridad convergen en la Ilustración, en los orígenes del Estado liberal, que acaba con el absolutismo. Un texto de Montesquieu será decisivo para entender la integración, cuando sostiene que la libertad política, en relación con los ciudadanos, consiste en la idea que cada uno tiene de su seguridad y que esta deriva de la 
situación de las leyes criminales. Es un paso más en la lucha contra el Derecho penal y procesal de la monarquía absoluta, que combatieron Tomasio, Beccaria o Voltaire, y que tan bien describe en su obra sobre el tema el inolvidable Francisco Tomás y Valiente.

Esta relación necesaria entre libertad y seguridad en el Estado de Derecho, que solo se quebrará con los totalitarismos fascistas —entre ellos el franquismo en España- y comunistas, se plasmará en un grupo específico de derechos fundamentales, que son las garantías procesales, y en el Estado social con los derechos económicos y sociales que producen seguridad frente al miedo a la enfermedad o a la muerte. En todo caso, se puede afirmar que la seguridad adquiere nuevos perfiles en el Estado liberal y en el social, y que se convierte en acompañante necesario de la libertad.

En el orden político futuro, no existen razones para romper ese vínculo porque la libertad no existe si no es segura. Por eso hay que llamar especialmente la atención después de los sucesos del 11 de septiembre, que humillan la seguridad de Estados Unidos y que, por consiguiente, afectan a su libertad. Cualquier reacción de venganza es inapropiada y ofende a los progresos de nuestra cultura democrática en ese campo. Todos los criminales, incluso los más despreciables, tienen derecho a las garantías procesales, y los tratos inhumanos o degradantes no pueden justificarse nunca por la barbarie de ningún delito. Es estremecedor ver a los talibanes presos, con una máscara que les tapa la boca, los ojos y los oídos, recibiendo un trato que el Tribunal Europeo de Derechos Humanos ha considerado como tortura. Parece que volvemos a la máscara de hierro y a las órdenes de prisión de la monarquía absoluta, justificadas con la escueta expresión de la voluntad regia: «car tel est mon plaisir», sin plazo y sin procedimiento. No puede haber dos raseros: el garantismo del due process of law y el trato cruel, porque volveríamos a la dialéctica del odio, y del amigo-enemigo, y no nos diferenciaríamos de los totalitarios de toda calaña que han existido en la historia.

VII.

Con esta reflexión, he apuntado las bases éticas, políticas y jurídicas del orden mundial del futuro, que deberían incardinarse en una serie de grandes problemas que sin duda se van a afrontar en este nuevo siglo, desde la superación de las soberanías excluyentes hasta la universalización de los derechos humanos, pasando por la globalización económica, por los problemas de pobreza, de hambre y de analfabetismo, con el enjuiciamiento en tribunales internacionales de los crímenes contra la humanidad y de genocidio, por el fenómeno de la emigración y por las nuevas conquistas de la ciencia y de la biotecnología. Para cada tiempo histórico, su momento es el siglo, eje de la humanidad. Para el futuro que afrontamos, nunca la humanidad ha estado mejor pertrechada de

LAS BASES

ÉTICAS,

POLITICAS Y

JURÍDICAS DEL

ORDEN MUNDIAL

FUTURO 
ideas, de depósitos de racionalidad y de medios técnicos. Como siempre, la lucidez, la generosidad, la cultura y la educación son virtudes indispensables para abordar ese futuro y, sobre todo, para respetar a cada uno, sus ideas, sus diferencias y su dignidad. Decía Fernando de los Ríos refiriéndose a España que en nuestro país siempre había faltado respeto. Pero parece que esa no es una tendencia negativa exclusiva de nuestro país. Desde este observatorio, se puede constatar que estamos ante un escenario generalizado, y es que el respeto es el signo del reconocimiento de la dignidad igual de todas las personas. Volvemos al principio: sin este núcleo duro de la ética pública de la modernidad, el futuro será incierto. Una vez más, el uso de la razón deberá ser el camino de la humanidad. 